\title{
Adolescent time use trends: France 1986 to 1998
}

\author{
Alain Chenu and Laurent Lesnard \\ CNRS-FNSP, Observatoire sociologique du changement \\ and INSEE-CREST, Laboratoire de sociologie quantitative \\ Paris
}

This paper examines changing patterns of adolescent time use in France from 1986 to 1998. It focuses on adolescents' aged 15 to 19, living at home with their parents, and attending school. It analyzes how the allocation of adolescent daily time is affected by respondents' gender, age, and by their parents' educational background and income. Data are taken from two national time use surveys conducted by INSEE (Institut National de la Statistique et des Etudes Economiques, Paris) in 1985-1986 ( $\mathrm{n}=16,046$, including 559 adolescents) and in 1998-1999 ( $\mathrm{n}=15,435$, including 1,193 adolescents). One of the main trends in the observed period is the shift in gender roles. In 1986, girls and boys spent the same amount of time in school-related activities, in 1998, this length was higher for girls. The gender gap in domestic work has slightly narrowed. All in all, girls' total work overload has increased. The allocation of time to work, personal needs and leisure remained similar, regardless of the educational level of parents. The allocation of free time to its various subcomponents is, however, affected by parents' education: children born in highly educated families spend more time reading, going to the movies, to the theater or to shows, less time watching TV, walking, or socializing. Parents' income level is less influential. Adolescents with middle-income parents work harder at school than those from lower or upper income families. 


\section{Introduction}

In spite of the gender convergence in adults' use of time, observed in economically developed countries (Gershuny, 2000), time use inequalities between men and women remain pronounced. Women still do the bulk of domestic and parental work ${ }^{1}$, while men are more involved in paid work. Our analyses serve as a reminder that gender inequalities in time use are not biological, but rather social in nature. Daily life plays a crucial role in maintaining social order and forming social differences. It is during the most mundane everyday activities and interactions that differentiated social dispositions are acquired and reinforced (Goffman, 1977). Yet, children's and adolescents' use of time is not as well documented as adults'. This article attempts to bridge this empirical gap.

The time use prism that is used in our analyses has considerable methodological advantages. Respondents are not asked to give self-estimates of the time they spent on a list of predefined activities but, instead, describe in their own words, the content of their daily life in a time diary. The sequential nature of this survey tool helps respondents to focus on the sequence of events that their daily life is made of. It has been long established that time use diaries are superior to "stylized" questions for "making serious time use projections for the population" (Robinson, 1985). It is possible, however, that this methodology, while providing accurate accounts of adults' daily life, is less adapted to children, whose temporal capabilities are not yet well established ${ }^{2}$. Most time use surveys therefore exclude young children ${ }^{3}$ from their samples, and interview only adolescents aged 15 and over. This practice was adopted in France. Only adolescent older than 15 years were interviewed in the two last

\footnotetext{
${ }^{1}$ For more detailed analysis of trends in parental work, see Sayer et al., 2004.

${ }^{2}$ For children's progressing understanding of the temporal structure of the society, see Elias (1992).

${ }^{3}$ Italy is a noteworthy exception: very young children (from the age of 3) were included in Italy's time use surveys. For an overview of the characteristics of national time use surveys, see the website of the Multinational Time Use Study project: http://www.iser.essex.ac.uk/mtus.
} 
French time use surveys and, as a result, this paper focuses on adolescents aged 15 to19.

Childhood is, historically, a relatively recent concept that is closely linked to the spread of schools (Ariès, 1960), itself highly correlated with industrialization (Thompson, 1960). According to Thompson, school education became compulsory in the UK in order to inculcate time discipline in future factory workers (Thompson, 1960). Time discipline was, indeed, a crucial factor in the emerging industrial economy, where division of labor required workers to specialize and synchronize their activities (Thompson, 1960; on the economic rhythm, see also Moore, 1963). Homebased workers of the pre-industrial era used to organize their work quite differently: instead of working every day, except for Sunday, they used to start the week by a few rest days (Sunday, but also Saint Monday and Saint Tuesday), and to concentrate paid work during the rest of the week. The new industrial rhythm was, in the beginnings, often enforced with physical violence, and was accepted by the factory workers only decades later ${ }^{4}$.

Compulsory schools partook in instilling time discipline. They were and still are based on strict schedules that both teachers and students are supposed to respect (Thompson, 1960). Punishments related to temporal offenses were an important part of school rules. The schools not only prepared future workers for factory imposed time discipline, but contributed to the emergence of childhood as a distinct period of life between infancy and adulthood (Ariès, 1960). With the introduction of the school system, education stopped to be a private matter or an apprenticeship, but rather became a specific phase of adulthood socialization. Children in the new system were neither infants nor money earning adults. They remained dependent but gained

\footnotetext{
${ }^{4}$ Factory workers eventually accepted this organization and began to fight for a reduction of working hours, rather than for the restoration of the old system (Thompson, 1960).
} 
autonomy. This new status occurred, while family solidarity relied increasingly on interpersonal relationships and less on the division of labor (Durkheim, 1921).

As childhood became integrated into the transition to adulthood, it has also altered the channels of social heredity. According to Bourdieu and Passeron (1970), social heredity began to be mediated by culture and education, hiding social reproduction as a result. The passage of social status became more dependent on the transmission of the cultural rather than the economic capital. Social reproduction became less certain, more hidden, and had to be legitimated by the school. The prominent role of education in the social struggle to preserve or improve hereditary privileges has increased the pressure on children. Children became, for parents, not a short-term economic resource but a costly investment.

In France, primary school became compulsory for boys and girls aged 6 to13 in 1881 and 1882, based on a series of laws passed under Jules Ferry. Girls could attend secondary schools since 1867 but, because these were not compulsory, attendance remained limited to girls from upper classes. Curricula of schools for girls were highly gendered and did not include science classes or vocational training (Lévy, 1992). Compulsory school was extended to 14 years in 1936 under the government of the Front Populaire and to 16 in 1959. Although first coeducational schools were opened in the 1950s, the coed structure was codified for all schools only in 1975. From then on, girls could get the same education as boys, with some survey evidence suggesting that the educational expectations of French parents may be higher with respect to girls than boys (Baudelot and Establet, 1992).

Family contributes to the social reproduction of gender rolesl. According to Berk (1985), family is a "gender factory", where parents pass gender roles onto their children. Following a little-known suggestion by Parsons and Bales (1955), Nancy 
Chodorow (1978) concluded that it will take more than an equal division of paid work between spouses to alter the functioning of the family as a "gender factory". The roots of gender roles do not lie, according to her, in the division of labor, paid or domestic, but in the division of men's and women's emotional contribution to the family.

Men do not participate in childcare to the same extent as women, because they are socialized differently. Becoming a man involves fighting emotional dispositions acquired during infancy. When it concerns caring and nurturing, masculinity is constructed in opposition to femininity. Girls dance, swim, do gymnastics and sports associated with feminine corporal characteristics, but many drop out of sport in adolescence (Cromer, 2005). Boys not only spend more time doing sport than girls, but the sports they choose have often a daring or exploit dimension.

The main question addressed in this article is, whether gender inequalities in time use are narrowing or not. According to Jonathan Gershuny (2000), from the 1960s on, a gender convergence in paid and unpaid work has occurred in the industrialized world. If this were correct, the daily life of French adolescents in the late 1990s would have been marked by fewer gender differences than in the 1980s. If the gender time use convergence was only temporary or did not apply to adolescents, then the everyday life of adolescents in France would become highly differentiated according to the type of the day observed, weekday or weekend, with time inequalities being possibly greater on weekends.

This article is coordinated with Jiri Zuzanek's and Roger Mannell's paper “Adolescent time use trends: Canada 1986 to 1998" presented at the 2003 IATUR conference Comparing Time in Brussels (Zuzanek, Mannel, 2003). The article examines changing patterns of adolescent time use in France from 1986 to 1998 by focusing on adolescents aged 15 to 19 , living at home with their parents (or at least 
with one parent), and attending school. It analyzes how the allocation of adolescent daily time is affected by respondents' gender, age, and family's cultural and economic resources.

\section{Data: 1986 and 1998 French time use surveys}

The samples of the 1986 and 1998 time use surveys are representative at a national level and have been conducted by the French public statistical administration (INSEE, Institut National de la Statistique et des Etudes Economiques). No interviews have been collected for the second half of December, nor for the first half of August. People were interviewed at their home. Applying the "tomorrow method", interviewers made a second visit to collect and control the 24-hour diary which was self-completed by respondents.

The 1986 time use survey was conducted between September 1985 and September 1986. In each household one person aged 15 or older was selected by the Kish method; his or her spouse, if any, was also interviewed $(\mathrm{N}=16,046)$. The 1998 time use survey was conducted between February 1998 and February 1999. In every household all residents aged 15 and older were eligible to be interviewed $(\mathrm{N}=15,435)$.

Two main methodological differences limit comparisons of time use in the two surveys. The minimum time interval for reporting activities was 5 minutes in 1986 and 10 minutes in 1998; thus, very short episodes (such as washing up, having a coffee break or a brief walk or drive...) may have been recorded in 1986 but missed in 1998. There were some differences in activity codes between the two surveys. In 1986, coding was done manually, in 1998 semi-automatically. As a result, common activity codes used in our analyses had to be simplified. We merged time spent at 
school and doing homework, night sleep and nap, eating at home and dining out, because distinctions between and within these activities may have been blurred by differences in coding. Sleeping and eating time lengths are probably overestimated in 1998.

\section{Adolescents and their diaries}

Among the 15 to 19 year old adolescents, $82 \%$ were students living with their parents in 1986, 90\% in 1998 ( Table 1). The size of the sub-sample of the 15 to 19 year old students living with their parents was 559 in 1986, and 1,198 in 1998.

Three kinds of diaries are considered: (a) Monday to Friday diaries with over 60 minutes of school work (at school or at home), (b) Saturday or Sunday diaries, and (c) other diaries (Monday to Friday with 60 or fewer minutes of school-related activities; mostly during school vacations). It is difficult to precisely distinguish holidays from the school year due to the fact that France is divided into zones with different school work schedules and these zones were not recorded in the survey file. Some students attended classes Saturday morning.

The share of week day diaries with more than one hour of school work significantly declined from $1986(52 \%)$ to 1998 (48\%, see Table 2). The gross frequencies of (a) diaries are 296 in 1986, and 606 in 1998, of (b) diaries, 161 and 340 respectively, and of (c) diaries 102 and 252.

\section{The homogenizing effects of school on adolescents' daily life}

In 1986, students aged 15 to 19 and living with parents reported on school days around 8.5 hours of school work. In 1998, school-related time on school days amounted to 8 hours (Table 4). Boys and girls spent the same amount of time in 1986 
in school-related activities - five hours per day when pro-rated over the entire week (Table 3). Twelve years later girls spent four and a half hours in school-related activities, that is quarter of an hour more than boys.

The allocation of school related time on week days and weekends is affected by gender. From Monday to Friday, when the daily amount of school work exceeds one hour, school related time is longer for boys than for girls. On weekend days, girls report doing more school-related work than boys (Table 4 and Table 5).

These differences can probably be attributed to the types of schools boys and girls attend. A lot of boys attend vocational programs, with longer time spent in classes and fewer hours of homework, while girls are more prone to take general courses, with shorter class time and more homework spread over the entire week. In other words, differences in school work durations echo the still pervading gender division of knowledge. Girls "prefer" to study literature and humanities at the expense of science studies and vocational training (Marry and Schweitzer, 2005).

Adolescence is today, by and large, defined by school and it is school that determines boys' and girls' daily lives. Regardless of the type of studies, school work is central in the everyday life of French adolescents, among others because of the parental pressure on children.

School is a "time structuring" institution. It requires a "time expenditure" on the part of children (Boudieu and Passeron, 1970, p. 251) and aims at inculcating in students a time order closely linked to the demands of economic life. Like economic time, school time is strictly defined and punctuality is central to it. Whether the rules are followed and integrated or are circumvented by shirkers, school is playing a 
crucial role in the temporal socialization of children ${ }^{5}$. Adolescents' daily life is in many ways structured quite similarly to the life of the adults employees or factory workers. Education, like paid work for adults, is homogenizing adolescents' daily life in terms of time use.

\section{Boys' and girls' personal needs - similarities and differences}

School seems to homogenize students' personal needs similar to the rest of their lives. The effects of this homogenization are, as might be expected, more obvious during school days than on weekends. On school days, boys spent approximately the same amount of time sleeping as girls did (529 minutes compared to girls' 522 in 1986, and 527 minutes compared to 535 in 1998). The same applies to eating. Both boys and girls spent on school days around 1.6 hours on it in 1986 and 1.9 hours in 1998. There was, however, a difference in the amount of time boys and girls spent on personal care and hygiene. In both, 1986 and 1998, girls spent more time on personal care than boys on school days, as well as weekends.

In both surveys, boys and girls spent considerably more time sleeping on weekends than they did on school days, and the gap between school day and weekend sleep has widened considerably in 1998. The direction of gender inequalities on weekends might have changed between 1986 and 1998. In 1986, boys slept on weekends longer than girls, while in 1998 it was the girls who reported a longer sleep. The same applies to eating. In 1986, boys reported more of it on weekends; in 1998 it was the girls. It seems that, differently than boys, who invested gains from the lower overall workload in 1998 primarily into free time, girls invested these gains mostly into personal needs.

\footnotetext{
${ }^{5}$ See also Elias (1992) on this aspect.
} 


\section{Hard working girls, lazy boys?}

Like for the adult population, for adolescents time outside of the structured context of work or school is more sensitive to gender variation. Both in 1986 and 1998, girls reported doing more domestic work than boys. In 1986, girls spent 1.7 hours per day on domestic work (housework, shopping, child and family care) compared to boys one hour. In 1998, it was somewhat less - 85 minutes for girls and 53 minutes for boys. On school days, adolescents are just helping out with housework. In 1998, girls allocated half an hour to housework and boys seventeen minutes. Their contribution was higher on weekends: one hour and twenty minutes for girls and forty-nine minutes for boys. Most shopping was done on school days with girls doing twice as much of it as boys (20 minutes compared to boys' 10 minutes, in both 1986 and 1998). The gap between boys' and girls' shopping, similar to housework, widened on weekends.

Paid work played a negligible role in the lives of French students in 1986 and 1998, with virtually no work reported on weekends.

When school related work, domestic obligations and paid work are combined, girls' workload appears to be greater than the boys' in both 1986 and 1998. The gap was somewhat wider in $1998(13 \%)$ than in $1986(9 \%)$ and much wider on weekends than on school days (33\% on weekends, compared to $3 \%$ on school days in 1998).

As a result, boys have more free time than girls, particularly on weekends, and this gap has widened. In 1998, boys reported having 6.4 hours of leisure on school days, compared to girls' 5.3 hours, and eight hours on weekend days compared to six hours and a half among girls (Table 5). 
The content of free time is also largely gendered. As expected, boys spend more time than girls doing sport, playing games and going to the cinema. To a lesser extent, boys also spend more time watching TV or videos. Girls spend more time reading, an activity which may often be closely related to school work..

In general, gendered inequalities are leveled during weekdays, owing to the equalizing effects of school, but are intensified on weekends. Non-school time of adolescents is dramatically marked by gender: boys do sport or watch TV, while girls help their mothers doing domestic chores and look after their appearance. These differences while present during school days are magnified on weekends, particularly in the domain of leisure.

\section{The gendered topology of time use}

Figure 1 provides summary analysis of the gendered topology of adolescent time use in 1998, within the context of the week. The horizontal axis displays the specialization indexes for weekdays and the vertical for weekends. Specialization indexes are defined here as the log ratio of girls' and boys' time spent in different activities under consideration ${ }^{6}$. Activities located in the North-East quadrant are "feminine" (more prevalent among girls) on weekdays and weekends. We find here, not surprisingly, domestic work, but also personal care and reading. Sleep, eating and school-related time are "gender-neutral" and appear accordingly in the center of Figure 1. TV and commuting time between home and school are also gender-neutral, albeit slightly more "masculine" (more prevalent among boys). Games and sport are masculine on weekdays as well as weekends, whereas movies are masculine only on weekends. Activities that are masculine (resp. feminine) on weekdays and feminine

\footnotetext{
${ }^{6}$ The logarithm transformation is used to make the index symmetrical. Some activities are not displayed given their negligible weight in French adolescents' daily life, for example, religion and participation in voluntary activities.
} 
(resp. masculine) on weekends are to be found in the North-West (resp. South-East) quadrants. Quite interestingly, there is no significant case of gender inversion: even when gender differences are minor in absolute terms during the week, the relative differences are always going in the same direction. School time is compressing and hiding gender inequalities, but does not remove them completely.

\section{Few differences between two age sub-groups}

Compared to the 15 to 17 years old respondents, 18 and 19 years old spend more time traveling to and from school. It is possible that they must go farther to reach more specialized colleges. Older teens spend more time on school work and paid work, less time sleeping but more on grooming, less time on walking, doing sport and playing games but more on socializing. These differences are, however, quite small. There is no time use gap between the two age groups of adolescents. Late adolescence appears to be temporally a relatively homogeneous period of life, defined largely by the demands of schooling.

\section{The effects of parents' cultural and economic resources}

The allocation of time to large categories of time use, such as school-related activities, personal needs, or free time, is affected by parents' educational level to a much lesser extent than adolescents' involvement in specific leisure activities (Table $6)^{7}$. Participation in leisure activities, clearly, depends on parents' education. Children born in highly educated families spend more time reading, going to the movies, to the theater or to shows, less time watching TV, doing sports, or socializing.

7 Due to the Kish method used in 1986, information about parents' educational level is not available for this year. 
When cumulated, daily differences in the use of leisure time form cultural capital or "taste culture" which subsequently determine educational achievement and career opportunities (Bourdieu, 1979). Analysis of adolescents' time use shows us that cultural inequalities can persist under the conditions of an equal access to school time. This helps us to understand, why schooling today takes longer than in the past. In essence, the transmission of cultural capital takes time than because it is not money but dispositions that are transmitted.

In 1998, adolescents living in middle income households spent more hours studying and working for pay, and had somewhat less free time than students from lower or upper income families. Parents' income level does not have as strong an effect on students' leisure preferences as education, but even so, students from high income families report higher levels of participation in leisure activities such as reading, social leisure, attending movies and sporting events, as well as games (Table 8).

\section{Discussion}

School represents for adolescents a structural equivalent of paid work for the adults. School puts claims to much of students' time and prepares them for their future economic activities. It requires and reinforces punctuality, timetables, organization, and anticipation. Parents' cultural and economic capital has a limited effect on adolescents' time dedicated to schoolwork. The overinvestment of time into school-related work by middle-class adolescents can be interpreted as cultural and social goodwill. 
Parental cultural and economic capital carries significant consequences for the use of free time. Adolescents born in upper-class families watch less television and read more. Cultural capital is transmitted outside of school, during free time and social inequalities are magnified on weekends.

Since much of adolescents' daily life is structured by school, which is equally accessible to boys and girls, gender inequalities in time use have almost vanished on school days. Boys' and girls' typical school day includes seven hours of schoolrelated work, one hour and a half of TV, close to two hours of eating, a few minutes of reading, doing sport, and helping out with housework. Girls may be spending more time than boys in doing domestic work but the absolute difference between the two genders is not very big. During school days, girls and boys are first and foremost high school students.

Gender awakens on weekend, though. When the temporal homogenizing effects of school lessen, gendered dispositions resurface in time budgets: girls' total workload on weekends is much higher than boys' and this gap widened between 1986 and 1998 . On weekends, girls contribute more to domestic work and look more after themselves (personal care and shopping). In other words, they are "doing gender" (West and Zimmerman, 1987). For their part, boys' time use masculinity is also magnified on weekends: they do sports, play games and go to the movies, in short, build up their physical prowess and engage in recreational leisure.

These results do not apply to France only, but are also found in Canada, Belgium and Finland (see articles in this issue of Loisir \& Societe). The mechanisms at work are common to all economically developed countries. Social competition and gender inequalities are linked to modern social organization rather than to a particular 
society. In view of the fact that adolescents of today are tomorrow's adults, our findings contradict Gershuny’s (2000: 4,73) notion of gender role convergence.

Gershuny drew attention to the effects of a major transformation that has affected to a greater or lesser extent every developed country, namely, the striking increase of women's participation in the labor force and a corollary replacement of male breadwinner families by dual-earner ones. The gender convergence observed between the 1960s and the 1990s may have been, however, temporary and resulted in a relatively limited adjustment of time use in the families. The rise in dual-earner couples naturally implied convergence in paid and unpaid work, because women had less time to put into domestic work. Gershuny acknowledged this by pointing out that the gender convergence in unpaid work was due, to a large extent, to the fact that women spent less time doing domestic chores rather than to a spectacular increase in men's domestic contribution.

The coexistence in the adolescents' daily life of relatively gender-neutral school time with strongly gendered off-school time suggests that gender temporal equality can be achieved in key daily activities (paid work, unpaid work, study) without affecting the rest of daily life. Since school is for adolescents, from a temporal perspective, the structural equivalent of adults' paid work, formal gender equality in accessing school need not lessen gender inequalities in the rest of students' everyday life. On the contrary, as the widening of the time use gap on weekends suggests, gender inequalities can increase outside of institutionalized daily activities.

An increase of gender inequality in time use, particularly on weekends, suggests that we are witnessing not a gender convergence but, at best, a stabilization of the gender gap and maybe even its divergence. Indeed, if the gender dispositions are reproduced by an unequal division of emotional and caring work between women and 
men (Chodorow, 1978), in brief by the parental hegemony of mothers, then women's entrance into the labor market will not reduce gender transmitted inequality, unless childcare in the parental families is redistributed more equally between spouses. Unfortunately, this does not seem to be the case. In a seminal analysis of the evolution of time spent by Americans in daily care for their children, Sayer et al. (2004) demonstrated that mothers' child care time increased dramatically since the 1960 s despite the rise in women's labor force participation. "Behavioral change", in the words of the authors, outweighed economic and structural change. In other words, far from being weakened by a more egalitarian distribution of paid work, feminine time use dispositions may have been preserved or even reinforced.

Findings presented in this article indirectly support the contention that the gender gap in time use has not been affected by dual-earning, and gender inequalities have gained ground since the mid 1980s. Future research should investigate the validity of the socio-psychoanalytic explanation of this phenomenon, suggested originally by Nancy Chodorow (1978). Time use studies can play a part in this effort, because they allow us to examine interactions within the family, where the co-presence of parents and children is reported. 


\section{References}

Ariès, Philippe (1960). L'enfant et la vie familiale sous l'Ancien Régime, Paris: Plon.

Baudelot, Chritian and Establet, Roger (1992). Allez les filles !, Paris: Seuil.

Berk, Sarah Fenstermaker (1985). The Gender Factory: The Apportionment of Work in American Households, New York: Plenum Press.

Bourdieu, Pierre and Passeron, Jean-Claude (1970). La reproduction : éléments pour une théorie du système d'enseignement, Paris: Minuit.

Bourdieu, Pierre (1979). La distinction. Critique sociale du jugement, Paris: Minuit.

Chodorow, Nancy J. (1978). The Reproduction of Mothering, Berkeley and Los Angeles: University of California Press.

Cromer, Sylvie (2005). "Vies privées des filles et garçons: des socialisations toujours différentielles ?", Maruani, Margaret (ed.) Femmes, genre et sociétés. L'état des savoirs, Paris: La découverte, 192-199.

Durkheim, Émile (1921). "La famille conjugale", Revue philosophique, 90, 9-14.

Elias, Norbert (1992). Time: An Essay, Oxford: Basil Blackwell.

Gershuny, Jonathan (2000). Changing Times: Work and Leisure in Postindustrial Society, Oxford: Oxford University Press.

Goffman, Erving (1977). "The arrangement between the sexes", Theory and Society, 4, 301-331.

Lévy, Marie-Françoise (1992). "L'éducation des filles. Approche historique", in Singly, François de (ed.) La famille : l'état des savoirs, Paris: La découverte, 211-220.

Marry, Catherine and Schweitzer, Sylvie (2005). "Scolarités", in Maruani, Margaret (ed.) Femmes, genre et sociétés. L'état des savoirs, Paris: La découverte, 212-217.

Moore, Wilbert E. (1963). Man, time, and society, New York and London: Wiley and sons.

Parsons, Talcott and Bales, Robert F. (1955). Family, Socialization and Interaction Process, Glencoe: The Free Press.

Robinson, John P. (1985). "The validity and reliability of diaries versus alternative time use measures", in Juster, F. Thomas and Stafford, Frank P. (ed.) Time, Goods, and Well-Being, Ann Arbor: University of Michigan Press.

Sayer, Liana C., Bianchi, Suzanne M., and Robinson, John P. (2004). "Are parents investing less in children? Trends in mothers- and fathers-time with children", American Journal of Sociology, 110, $1-43$.

Thompson, Edward P. (1967). "Time, Work-Discipline, and Industrial Capitalism", Past and Present, 38, 56-97.

West, Candace and Zimmerman, Don H. (1987). "Doing Gender”, Gender and Society, 1, 125-151.

Zuzanek, Jiri, and Mannell, Roger (2003). "Adolescent time use trends: Canada 1986 to 1998", Brussels, unpublished communication to IATUR conference. 


\section{Tables and figure}

Table 1 - Population aged 15-19 by occupation status and family composition, France 1986, 1998 (weighted \%). Source: INSEE, Time Use Surveys.

\begin{tabular}{|c|c|c|c|c|c|c|c|c|}
\hline & \multicolumn{8}{|c|}{ Position in the household } \\
\hline & \multicolumn{4}{|c|}{1986 (total: 100.0) } & \multicolumn{4}{|c|}{1998 (total: 100.0) } \\
\hline & Head & Spouse & Child & Other & Head & Spouse & Child & Other \\
\hline Employed & 0.2 & 0.2 & 7.5 & 0.0 & 0.1 & 0.3 & 4.4 & 0.2 \\
\hline Unemployed & 0.1 & 0.4 & 5.4 & 0.2 & 0.1 & 0.0 & 2.6 & 0.1 \\
\hline Student & 0.9 & 0.2 & 82.2 & 0.7 & 1.1 & 0.1 & 89.9 & 0.8 \\
\hline Other & 0.0 & 0.4 & 1.4 & 0.1 & 0.0 & 0.1 & 0.4 & 0.0 \\
\hline
\end{tabular}

Table 2 - Students aged 15 to 19 by type of day, France 1986, 1998 (weighted \%). Source: INSEE, Time Use Surveys.

\begin{tabular}{|l|ccc|c|}
\hline & $\begin{array}{c}\text { Monday to Friday, } \\
\text { over 60 min. of } \\
\text { school work }\end{array}$ & Saturday, Sunday & Other days & Total \\
\hline 1986 & 52.3 & 29.6 & 18.0 & 100.0 \\
1998 & 47.9 & 32.0 & 20.1 & 100.0 \\
\hline
\end{tabular}


Table 3 - Adolescent time use by gender, age, all days - France, 1986, 1998, students aged 15 to 19 living with their parents (min. per day). Source: INSEE, Time Use Surveys.

\begin{tabular}{|c|c|c|c|c|c|c|c|c|c|c|c|c|c|c|c|}
\hline & \multicolumn{5}{|c|}{1986} & \multicolumn{5}{|c|}{1998} & \multicolumn{5}{|c|}{ Variation 1986-1998 $(1986=100)$} \\
\hline & Total & Boys & Girls & 15-17 & 18-19 & Total & Boys & Girls & 15-17 & 18-19 & Total & Boys & Girls & $15-17$ & 18-19 \\
\hline Unweighted frequency & 559 & 276 & 283 & 380 & 179 & 1198 & 591 & 607 & 774 & 424 & . & . & . & . & . \\
\hline SCHOOL RELATED TIME & 301 & 302 & 300 & 303 & 297 & 263 & 255 & 270 & 256 & 274 & 87 & 84 & 90 & 85 & 92 \\
\hline School and homework & 265 & 265 & 265 & 268 & 256 & 236 & 228 & 244 & 231 & 245 & 89 & 86 & 92 & 86 & 95 \\
\hline Travelling to/from school & 37 & 37 & 36 & 35 & 41 & 27 & 27 & 27 & 25 & 29 & 72 & 71 & 74 & 72 & 72 \\
\hline PAID WORK & 16 & 20 & 13 & 9 & 32 & 11 & 14 & 9 & 10 & 13 & 69 & 70 & 68 & 114 & 40 \\
\hline DOMESTIC WORK & 79 & 59 & 101 & 81 & 75 & 69 & 53 & 85 & 67 & 73 & 88 & 90 & 85 & 83 & 97 \\
\hline Housework & 61 & 46 & 77 & 63 & 58 & 51 & 40 & 61 & 48 & 55 & 83 & 86 & 79 & 76 & 96 \\
\hline Shopping and errands & 15 & 10 & 20 & 14 & 15 & 15 & 10 & 20 & 15 & 15 & 104 & 105 & 101 & 107 & 97 \\
\hline Child and family care & 3 & 3 & 4 & 3 & 3 & 3 & 3 & 4 & 4 & 3 & 108 & 105 & 109 & 108 & 110 \\
\hline TOTAL WORK LOAD & 397 & 381 & 414 & 393 & 405 & 343 & 322 & 364 & 334 & 360 & 86 & 85 & 88 & 85 & 89 \\
\hline PERSONAL NEEDS & 727 & 724 & 730 & 729 & 721 & 746 & 734 & 758 & 752 & 735 & 103 & 101 & 104 & 103 & 102 \\
\hline Sleep & 561 & 562 & 560 & 568 & 546 & 576 & 572 & 581 & 584 & 564 & 103 & 102 & 104 & 103 & 103 \\
\hline Eating & 108 & 112 & 104 & 106 & 111 & 123 & 123 & 123 & 123 & 122 & 114 & 110 & 118 & 116 & 110 \\
\hline Personal care & 58 & 50 & 66 & 55 & 64 & 47 & 40 & 54 & 45 & 50 & 81 & 79 & 82 & 83 & 77 \\
\hline $\begin{array}{l}\text { VOLUNTARY } \\
\text { ORGANISATIONS }\end{array}$ & 2 & 1 & 2 & 2 & 1 & 1 & 2 & 1 & 1 & 2 & n.s. & n.s. & n.s. & n.s. & n.s. \\
\hline RELIGIOUS ACTIVITIES & 1 & 1 & 1 & 1 & 1 & 1 & 1 & 1 & 1 & 0 & n.s. & n.s. & n.s. & n.s. & n.s. \\
\hline FREE TIME & 314 & 333 & 294 & 315 & 312 & 349 & 381 & 317 & 352 & 343 & 111 & 115 & 108 & 112 & 110 \\
\hline Watching TV and video & 111 & 118 & 104 & 115 & 103 & 125 & 127 & 123 & 125 & 125 & 112 & 108 & 118 & 109 & 121 \\
\hline Reading & 21 & 19 & 23 & 22 & 19 & 17 & 15 & 18 & 17 & 15 & 80 & 82 & 78 & 80 & 80 \\
\hline Social leisure & 52 & 43 & 61 & 47 & 62 & 75 & 76 & 74 & 69 & 85 & 144 & 175 & 121 & 146 & 138 \\
\hline Walking, sport & 41 & 52 & 29 & 46 & 32 & 43 & 55 & 30 & 47 & 34 & 103 & 105 & 103 & 104 & 106 \\
\hline Movies, culture & 22 & 25 & 18 & 22 & 21 & 20 & 22 & 17 & 21 & 17 & 91 & 89 & 95 & 96 & 81 \\
\hline Games & 18 & 23 & 12 & 19 & 17 & 29 & 43 & 15 & 31 & 25 & 160 & 183 & 122 & 167 & 147 \\
\hline Rest & 5 & 4 & 6 & 5 & 5 & 7 & 7 & 7 & 7 & 7 & 145 & 182 & 117 & 142 & 148 \\
\hline Travelling (not for work) & 45 & 49 & 40 & 41 & 53 & 35 & 36 & 34 & 35 & 34 & 78 & 74 & 84 & 86 & 65 \\
\hline
\end{tabular}


Table 4 - Adolescent time use by gender, age: Monday to Friday, class time over 60 min - France, 1986, 1998, students aged 15 to 19 living with their parents (min. per day). Source: INSEE, Time

Use Surveys

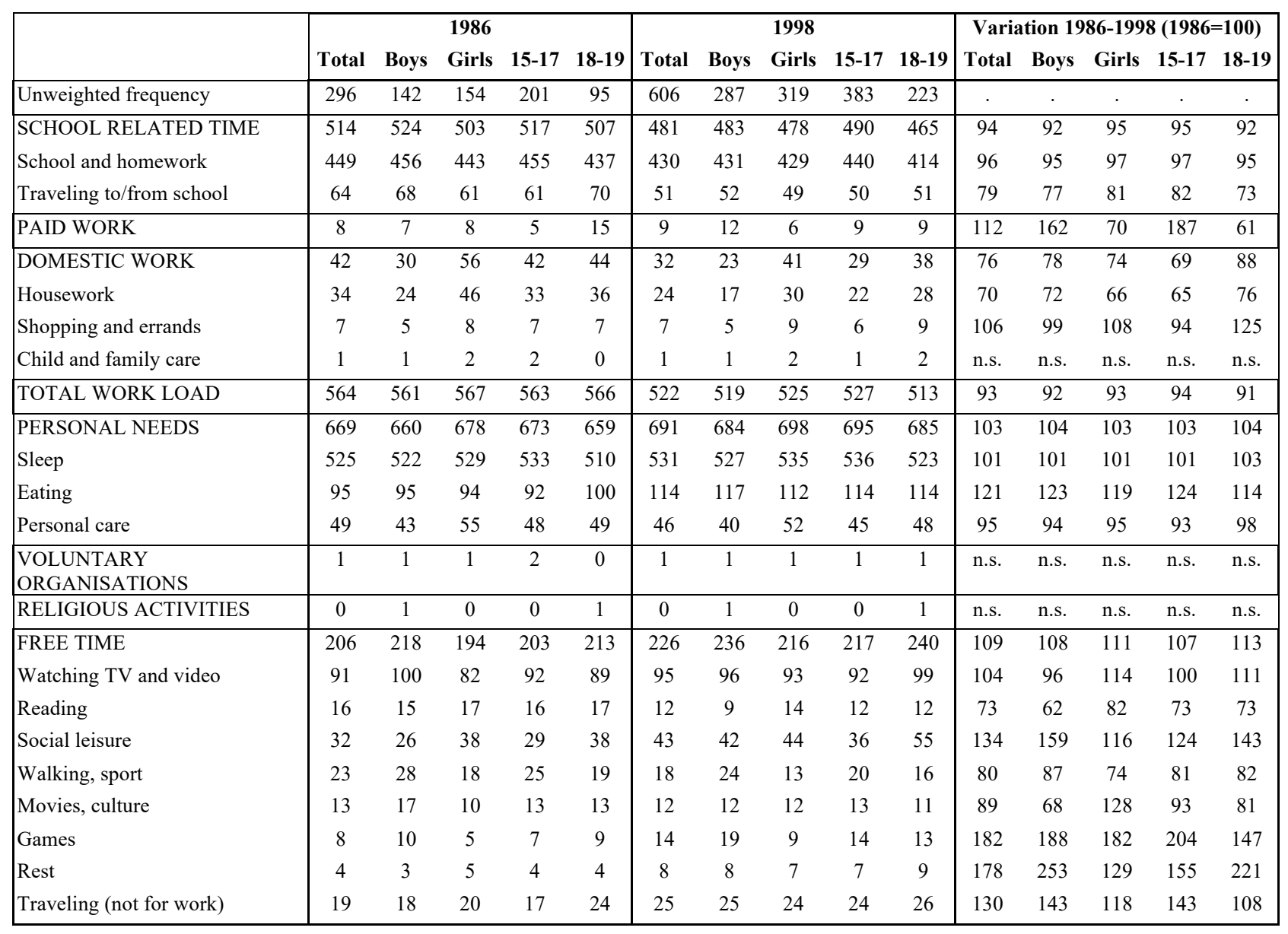


Table 5 - Adolescent time use by gender, age: weekends - France, 1986, 1998, students aged 15 to 19 living with their parents (min. per day). Source: INSEE, Time Use Surveys.

\begin{tabular}{|c|c|c|c|c|c|c|c|c|c|c|c|c|c|c|c|}
\hline & \multicolumn{5}{|c|}{1986} & \multicolumn{5}{|c|}{1998} & \multicolumn{5}{|c|}{ Variation 1986-1998 (1986=100) } \\
\hline & Total & Boys & Girls & $15-17$ & $18-19$ & Total & Boys & Girls & 15-17 & $18-19$ & Total & Boys & Girls & $15-17$ & 18-19 \\
\hline Unweighted frequency & 161 & 83 & 78 & 108 & 53 & 340 & 166 & 174 & 217 & 123 & . & . & . & . & . \\
\hline SCHOOL RELATED TIME & 103 & 98 & 107 & 101 & 107 & 93 & 90 & 96 & 83 & 111 & 91 & 91 & 90 & 82 & 104 \\
\hline School and homework & 96 & 93 & 99 & 93 & 101 & 89 & 85 & 92 & 79 & 106 & 92 & 92 & 92 & 84 & 105 \\
\hline Traveling to/from school & 7 & 6 & 8 & 7 & 6 & 4 & 5 & 4 & 4 & 5 & 65 & 78 & 55 & 55 & 88 \\
\hline PAID WORK & 8 & 13 & 2 & 7 & 9 & 4 & 6 & 1 & 5 & 1 & 48 & 48 & 65 & 71 & 16 \\
\hline DOMESTIC WORK & 107 & 81 & 135 & 107 & 105 & 92 & 66 & 118 & 88 & 99 & 86 & 81 & 87 & 82 & 94 \\
\hline Housework & 82 & 65 & 102 & 84 & 78 & 65 & 49 & 81 & 60 & 75 & 79 & 76 & 79 & 71 & 95 \\
\hline Shopping and errands & 20 & 11 & 29 & 19 & 20 & 20 & 11 & 29 & 22 & 18 & 104 & 104 & 100 & 113 & 89 \\
\hline Child and family care & 5 & 5 & 4 & 4 & 7 & 7 & 5 & 8 & 7 & 6 & 138 & 95 & 201 & 184 & 87 \\
\hline TOTAL WORK LOAD & 217 & 192 & 245 & 215 & 221 & 189 & 162 & 216 & 176 & 212 & 87 & 84 & 88 & 82 & 96 \\
\hline PERSONAL NEEDS & 779 & 779 & 778 & 785 & 766 & 810 & 787 & 833 & 815 & 802 & 104 & 101 & 107 & 104 & 105 \\
\hline Sleep & 591 & 595 & 586 & 591 & 591 & 622 & 611 & 633 & 628 & 613 & 105 & 103 & 108 & 106 & 104 \\
\hline Eating & 127 & 135 & 118 & 132 & 116 & 139 & 134 & 144 & 141 & 136 & 110 & 100 & 122 & 107 & 117 \\
\hline Personal care & 61 & 49 & 74 & 62 & 59 & 49 & 41 & 56 & 46 & 53 & 80 & 84 & 75 & 74 & 90 \\
\hline $\begin{array}{l}\text { VOLUNTARY } \\
\text { ORGANISATIONS }\end{array}$ & 3 & 1 & 6 & 4 & 2 & 2 & 4 & 0 & 1 & 3 & n.s. & n.s. & n.s. & n.s. & n.s. \\
\hline RELIGIOUS ACTIVITIES & 2 & 3 & 2 & 3 & 1 & 1 & 1 & 1 & 2 & 0 & n.s. & n.s. & n.s. & n.s. & n.s. \\
\hline FREE TIME & 439 & 465 & 409 & 433 & 450 & 438 & 486 & 390 & 446 & 423 & 100 & 105 & 95 & 103 & 94 \\
\hline Watching TV and video & 133 & 138 & 129 & 127 & 148 & 139 & 146 & 132 & 140 & 137 & 104 & 106 & 102 & 111 & 93 \\
\hline Reading & 23 & 19 & 28 & 24 & 22 & 19 & 18 & 19 & 20 & 16 & 80 & 92 & 70 & 83 & 75 \\
\hline Social leisure & 75 & 58 & 93 & 73 & 77 & 98 & 101 & 94 & 88 & 115 & 131 & 174 & 101 & 120 & 149 \\
\hline Walking, sport & 67 & 90 & 41 & 72 & 56 & 58 & 73 & 44 & 67 & 43 & 87 & 81 & 107 & 93 & 76 \\
\hline Movies, culture & 31 & 30 & 33 & 31 & 31 & 29 & 34 & 23 & 31 & 24 & 93 & 115 & 72 & 100 & 79 \\
\hline Games & 29 & 40 & 17 & 30 & 28 & 43 & 61 & 25 & 46 & 36 & 146 & 153 & 143 & 156 & 130 \\
\hline Rest & 5 & 5 & 5 & 5 & 4 & 6 & 5 & 6 & 6 & 6 & 122 & 115 & 128 & 109 & 151 \\
\hline Traveling (not for work) & 75 & 86 & 63 & 71 & 84 & 47 & 48 & 45 & 48 & 45 & 62 & 56 & 72 & 67 & 54 \\
\hline
\end{tabular}


Table 6 - Adolescent time use by parents' certification level: France, students aged 15 to 19 living with their parents, 1998 (min. per day). Source: INSEE, Time Use Survey.

\begin{tabular}{|c|c|c|c|}
\hline & \multicolumn{3}{|c|}{ A 11 days } \\
\hline Parents' diploma level* & 1 & 2 & 3 \\
\hline Unweighted frequency & 444 & 416 & 326 \\
\hline SCHOOL RELATED TIME & 251 & 255 & 286 \\
\hline School and homework & 224 & 229 & 260 \\
\hline Traveling to/from school & 27 & 26 & 26 \\
\hline PAID WORK & 10 & 15 & 8 \\
\hline DOMESTIC WORK & 79 & 64 & 63 \\
\hline Housework & 55 & 46 & 49 \\
\hline Shopping and errands & 20 & 13 & 12 \\
\hline Child and family care & 4 & 4 & 2 \\
\hline TOTAL WORK LOAD & 339 & 334 & 357 \\
\hline PERSONAL NEEDS & 746 & 750 & 740 \\
\hline Sleep & 578 & 583 & 565 \\
\hline Eating & 120 & 121 & 128 \\
\hline Personal care & 47 & 46 & 48 \\
\hline $\begin{array}{l}\text { VOLUNTARY } \\
\text { ORGANISATIONS }\end{array}$ & 1 & 2 & 0 \\
\hline RELIGIOUS ACTIVITIES & 1 & 1 & 1 \\
\hline FREE TIME & 353 & 354 & 341 \\
\hline Watching TV and video & 137 & 131 & 103 \\
\hline Reading & 12 & 16 & 25 \\
\hline Social leisure & 80 & 72 & 70 \\
\hline Walking, sport & 48 & 42 & 38 \\
\hline Movies, culture & 16 & 22 & 23 \\
\hline Games & 23 & 28 & 38 \\
\hline Rest & 6 & 7 & 7 \\
\hline Traveling (not for work) & 32 & 36 & 38 \\
\hline
\end{tabular}

* 1 = vocational training certificate or less; 2 = intermediate; 3 = high school diploma or more. 
Table 7 - Students aged 15 to 19 by type of day observed, and by parents' income level, France 1986 and 1998 (weighted \%). Source: INSEE, Time Use Survey.

\begin{tabular}{|l|ccc|c|c|c|c|}
\hline & \multicolumn{4}{|c|}{1986} & \multicolumn{3}{c|}{1998} \\
\hline $\begin{array}{l}\text { Household income, } \\
\text { by consumption } \\
\text { unit*: quartile }\end{array}$ & $\begin{array}{c}\text { Monday to } \\
\text { Friday, over } \\
\text { 60 min. of } \\
\text { school work }\end{array}$ & $\begin{array}{c}\text { Saturday, } \\
\text { Sunday }\end{array}$ & Other days & Total & $\begin{array}{c}\text { Monday to } \\
\text { Friday, over } \\
\text { 60 min. of } \\
\text { school work }\end{array}$ & $\begin{array}{c}\text { Saturday, } \\
\text { Sunday }\end{array}$ & $\begin{array}{c}\text { Other days } \\
\text { Total }\end{array}$ \\
\hline 1 & 49.0 & 34.2 & 16.8 & 100.0 & 44.7 & 33.4 & 21.9 \\
2 & 55.6 & 28.2 & 16.2 & 100.0 & 51.7 & 30.8 & 17.5 \\
3 & 47.0 & 25.9 & 27.1 & 100.0 & 53.0 & 27.2 & 19.8 \\
4 & 52.2 & 30.1 & 17.7 & 100.0 & 43.4 & 36.8 & 100.0 \\
\hline
\end{tabular}

* Consumption units are defined according to the EU-equivalent scale: The first adult in the household counts as 1 unit, the other adults 0.5 each, and every child under the age of 17 counts as 0.3 units.

Table 8 - Adolescent time use by income level: France, 1986, 1998, students aged 15 to 19 living with their parents (min. per day). Source: INSEE, Time Use Surveys.

\begin{tabular}{|c|c|c|c|c|c|c|c|c|}
\hline & \multicolumn{8}{|c|}{ A ll d a y s } \\
\hline & \multicolumn{4}{|c|}{1986} & \multicolumn{4}{|c|}{1998} \\
\hline $\begin{array}{l}\text { Household income quartile (by } \\
\text { consumption unit) }\end{array}$ & 1 & 2 & 3 & 4 & 1 & 2 & 3 & 4 \\
\hline Unweighted frequency & 129 & 125 & 101 & 86 & 409 & 275 & 236 & 252 \\
\hline SCHOOL RELATED TIME & 272 & 324 & 293 & 311 & 237 & 282 & 289 & 259 \\
\hline School and homework & 239 & 283 & 259 & 275 & 212 & 251 & 259 & 238 \\
\hline Traveling to/from school & 33 & 41 & 34 & 36 & 25 & 31 & 30 & 21 \\
\hline PAID WORK & 31 & 10 & 21 & 5 & 7 & 13 & 18 & 11 \\
\hline DOMESTIC WORK & 84 & 68 & 93 & 65 & 78 & 68 & 65 & 57 \\
\hline TOTAL WORK LOAD & 386 & 403 & 407 & 381 & 321 & 364 & 372 & 326 \\
\hline PERSONAL NEEDS & 738 & 726 & 731 & 712 & 752 & 740 & 739 & 751 \\
\hline Sleep & 573 & 550 & 566 & 554 & 584 & 575 & 565 & 577 \\
\hline Eating & 115 & 109 & 103 & 107 & 122 & 118 & 128 & 125 \\
\hline Personal care & 50 & 67 & 61 & 52 & 47 & 48 & 47 & 48 \\
\hline $\begin{array}{l}\text { VOLUNTARY } \\
\text { ORGANISATIONS }\end{array}$ & 0 & 1 & 0 & 7 & 1 & 1 & 1 & 2 \\
\hline RELIGIOUS ACTIVITIES & 1 & 1 & 0 & 2 & 1 & 1 & 0 & 0 \\
\hline FREE TIME & 315 & 310 & 302 & 338 & 364 & 334 & 327 & 361 \\
\hline Watching TV and video & 114 & 108 & 114 & 105 & 138 & 123 & 123 & 107 \\
\hline Reading & 13 & 18 & 17 & 26 & 17 & 13 & 17 & 20 \\
\hline Social leisure & 56 & 40 & 54 & 65 & 83 & 68 & 58 & 82 \\
\hline Walking, sport & 49 & 49 & 31 & 43 & 50 & 41 & 39 & 37 \\
\hline Movies, culture & 18 & 17 & 33 & 22 & 16 & 23 & 16 & 28 \\
\hline Games & 22 & 16 & 9 & 19 & 25 & 25 & 27 & 43 \\
\hline Rest & 4 & 8 & 4 & 5 & 6 & 8 & 8 & 6 \\
\hline Traveling (not for work) & 38 & 54 & 40 & 53 & 31 & 34 & 39 & 38 \\
\hline
\end{tabular}


Figure 1 - Specialization index for weekdays and weekend in 1998. Index are positive when girls are spending more time in the activity considered.

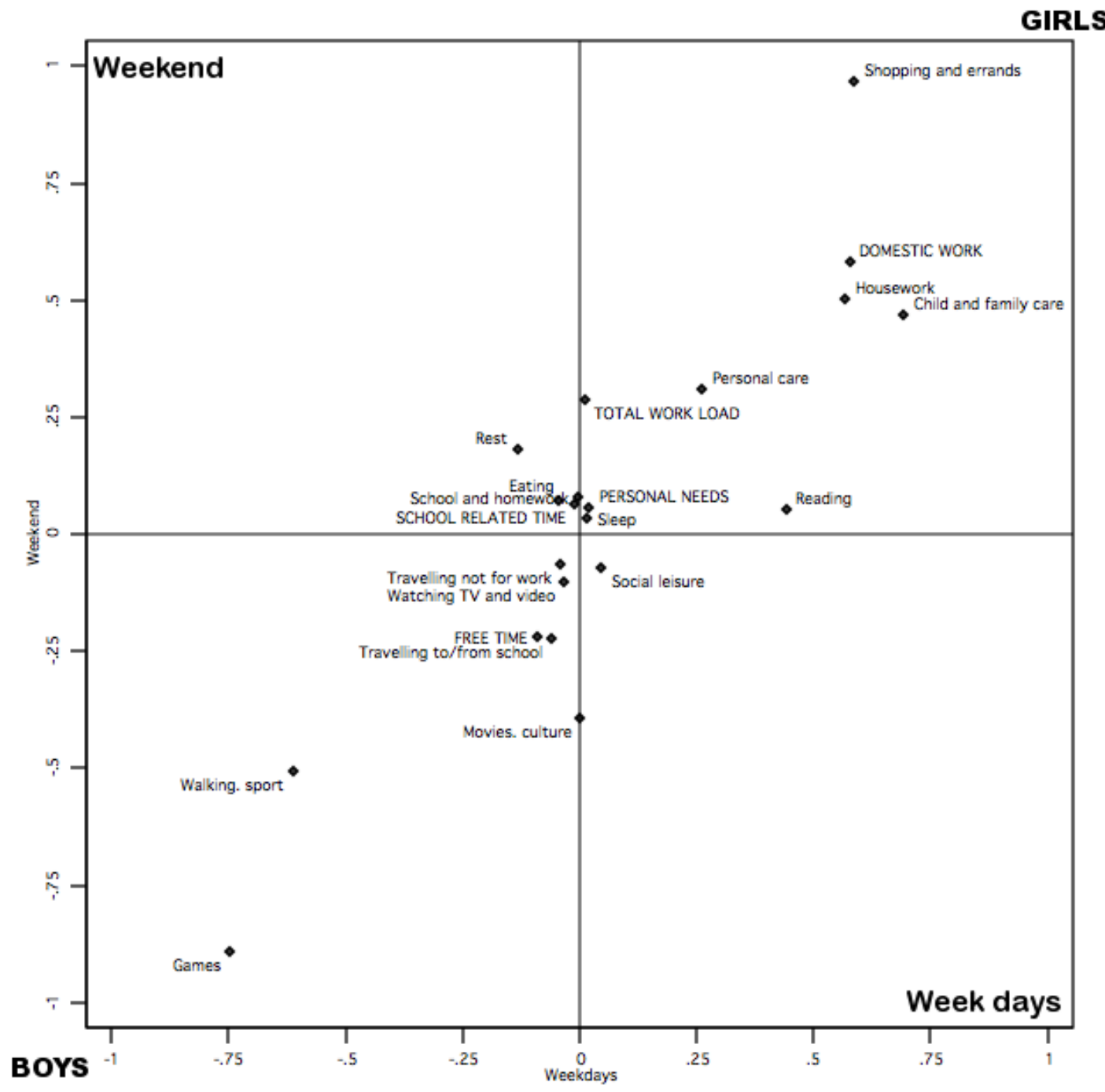

